\title{
Assessment of autonomic nervous function in patients with vibration syndrome using heart rate variation and plasma cyclic nucleotides
}

\author{
N Harada, H Kondo, K Kimura
}

\begin{abstract}
A case-control study was performed to investigate the autonomic nervous function in vibration syndrome. The subjects were 20 patients with a history of Raynaud's phenomenon (vibration white finger (VWF) (+) group), 20 patients without such a history (VWF ( - ) group), and 20 healthy workers (control group). Their ages and years under medical treatment for vibration syndrome were matched individually among the groups. They were examined using the test of $R-R$ interval variations in the electrocardiogram at rest and during deep breathing and the test of plasma cyclic nucleotide (cyclic AMP and cyclic GMP) responses to whole body exposure to cold. The heart rate variation resulting from respiratory arrhythmia reflects parasympathetic activity; the changes of plasma cyclic AMP and GMP levels reflect sympathetic and parasympathetic receptor functions. The reduced $R-R$ interval variations were observed in the VWF $(+)$ group. Although exposure to cold induced a significant increase of plasma cyclic AMP level, the percentage increase was almost the same among the three groups. The response of plasma cyclic GMP level to cold exposure was highly activated in the VWF(+) and the VWF $(-)$ groups. On the basis of these results, it is considered that the parasympathetic function of patients with vibration syndrome is lower at rest, and that exposure to cold induces a hypperresponse of the parasympathetic nervous system and the alpha-2 adrenergic mechanism as a result of activation of the sympathetic nervous system. Moreover, in patients with VWF, the contribution of the alpha-2 adrenergic mechanism is presumably larger than that in the patients without VWF.
\end{abstract}

Department of Public Health, Ehime University School of Medicine, Shigenobu, Ehime, Japan N Harada, H Kondo, K Kimura
The general symptoms of the vibration syndrome have been much discussed. Disturbance of the central nervous system has been suggested on the basis of subjective symptoms ${ }^{1}$ and the findings of electroencephalography. ${ }^{2}$ The Committee of Vibration Hazard in the Japanese Association of Industrial Health suggested that the central nervous system, the autonomic nervous system, and the endocrine system may be affected by vibration exposure to the handarm system. ${ }^{3}$ On the other hand, it has been pointed out that no objective evidence has been observed to confirm this proposal. ${ }^{45}$ In particular, evaluation of the autonomic nervous function is difficult and the tests available for this purpose are insufficient.

New non-invasive methods have been developed recently. With these methods, some researchers have indicated that variations in the $R-R$ interval of the electrocardiogram (ECG) was reduced in the workers exposed to vibration. ${ }^{6-8}$ Other researchers reported that the response of plasma cyclic guanosine 3',5'-monophosphate (cyclic GMP) level to cold exposure was increased in patients with the vibration syndrome. ${ }^{9}$ These results indicate that autonomic nervous function may be affected by vibration exposure to the hand-arm system. These studies, however, did not have age matched control subjects for testing variation in the R-R which is strongly affected by aging. For the test of the response of plasma cyclic GMP level, only the hand was exposed to cold. To activate the sympathetic nervous function of the patients with vibration syndrome, exposure to cold of the whole body is considered to be more suitable, because vibration induced white finger (VWF), the most characteristic symptom in the vibration syndrome, is provoked by the whole body cooling rather than by hand cooling.

We improved these methods and performed a comparative study of autonomic nervous function between patients with vibration syndrome and age matched control subjects. We describe the results of $R-R$ interval variation and the responses of plasma cyclic adenosine $3^{\prime}, 5^{\prime}$-monophosphate (cyclic AMP) and cyclic GMP levels to exposure to cold. 
Table 1 Number of subjects, age, height, weight, period of exposure to vibration, and period under treatment

\begin{tabular}{|c|c|c|c|c|c|c|}
\hline & No & Age (y) & Height $(\mathrm{cm})$ & Weight (kg) & Exposure (y) & Therapy (y) \\
\hline $\begin{array}{l}\text { VWF }(+) \text { group } \\
\text { VWF }(-) \text { group } \\
\text { Control group }\end{array}$ & $\begin{array}{l}20 \\
20 \\
20\end{array}$ & $\begin{array}{l}56.2 \pm 4.8 \\
55.8 \pm 5.0 \\
55.6 \pm 4.8\end{array}$ & $\begin{array}{l}162.4 \pm 4.6 \\
162.2 \pm 4.0 \\
163.6 \pm 5.9\end{array}$ & $\begin{array}{l}58.2 \pm 6.5 \\
58.5 \pm 7.8 \\
61.0 \pm 5.8\end{array}$ & $\begin{array}{l}20.1 \pm 8.0 \\
18.0 \pm 7.3\end{array}$ & $\begin{array}{l}7.7 \pm 5.9 \\
7.9 \pm 5.6\end{array}$ \\
\hline
\end{tabular}

$\mathrm{VWF}=$ Vibration white finger.

\section{Subjects}

The subjects were 40 patients with vibration syndrome under medical treatment $(\mathrm{VWF}(+)$ group and VWF(-) group) and 20 healthy workers (C group). The VWF $(+)$ group contained 20 patients with a history of Raynaud's phenomenon induced by exposure to vibration during the past year and the VWF(-) group contained 20 patients without a hisory of Raynaud's phenomenon but with finger numbness or paresthaesia. Seventeen patients in the $\operatorname{VWF}(+)$ group and 16 in the $\operatorname{VWF}(-)$ group had been rock drill operators in mines or in tunnelling works. The other patients had been chipping hammer and grinder operators in factories or chain saw operators in forestries.

The subjects were men aged between 45 and 64 who did not have pneumoconiosis, diabetes mellitus, hypertension, heart disease, liver disease, or a history of cerebrovascular disease. They were individually matched according to age, within a four year range, among the three groups. Also, between the $\operatorname{VWF}(+)$ and VWF $(-)$ groups, the subjects were individually matched according to years of medical treatment for vibration syndrome within a three year range. The means of age, years exposed to vibration, years under medical treatment, body height and body weight showed no significant difference between the three groups (table 1). All drug treatment was terminated three days before the test.

\section{Methods}

Subjective symptoms were assessed using the Cornell medical index-health questionnaire $(\mathrm{CMI})^{10}$ and the previous history of the subjects was determined before the experiment.

$\mathbf{R}-\mathbf{R}$ intervals were measured during two states, resting and deep breathing. The subject had to lie on his back and relax. After 20 minutes rest, the electrocardiogram from the limb leads was recorded in a data recorder (R-61, TEAC) for two minutes. After that, the electrocardiogram was recorded during deep breathing of regular inspiration and expiration in five second intervals for two minutes. During resting and deep breathing, the R-R intervals of 64 serial beats were analysed using a signal processing system (ATAC 2300, Nihon Kohden).

Cyclic nucleotide levels were also measured in two states. Firstly, the subject was required to sit and blood was drawn after 25 minutes. Then the subject moved and sat in a cold room at a temperature of $7^{\circ} \mathrm{C} \overrightarrow{\vec{H}}$ and blood was drawn after 25 minutes (cold exposure $\stackrel{\sigma}{\sigma}$ test). For this test, the subjects wore two pieces of $\stackrel{\varnothing}{\varnothing}$ clothing on the upper half and lower half of the body. 3 During the cold exposure test, skin temperature of $t$ middle finger (left or right) and blood pressure of the is upper arm were measured. The plasma was divided $i$ from the blood using a centrifugal separator at $4^{\circ} \mathrm{C} \mathrm{C}$ and frozen at $-70^{\circ} \mathrm{C}$. Cyclic nucleotide (cyclic AMP 음 and cyclic GMP) levels were analysed using RI assay kit (Yamasa). ${ }^{11}$

Sampling of the electrocardiograms and the blood for measuring cyclic nucleotide levels was performed $\overrightarrow{0}$ from 1300 to 1500 and from 1000 to 1200 , respec- $\bigcirc$ tively, in November 1984. The temperature of the test room for rest condition was kept at $25^{\circ} \mathrm{C}$ except during the period of the cold exposure. For statistical tests, the paired $t$ test and the F test were used.

\section{Results}

Table 2 shows the results of the investigation of $\overrightarrow{\overrightarrow{0}}$ health status using the CMI questionnaire. The 3 numbers of positive responses to physical items and psychological items of the $\operatorname{VWF}(+)$ and the VWF $(-)$ groups were larger than those of the $\stackrel{\varnothing}{\circ}$ control group $(p<0.01)$. The mean positive res- 3 ponse rates of the VWF $(+)$ group were $33.1 \%$ for physical items and $28.4 \%$ for psychological items. The rates of the VWF( $(-)$ group were $32.0 \%$ and 8 $26.9 \%$, respectively and the rates of the control group, $10.3 \%$ and $5.9 \%$.

Table 3 shows the means, standard deviations, and $D$ the coefficient of variations $(C V)$ of $R-R$ intervals at $\stackrel{\text {. }}{=}$ rest and during deep breathing. The $\mathrm{CV}$ is obtained $\bar{N}$ by dividing the standard deviation by the mean value. $\%$ Mean values of $R-R$ intervals do not statistically $N$ differ between the VWF $(+)$ group, the VWF $(-)$ N

Table 2 Number of positive responses to CMI questionnaire. In total 160 items of physical condition and 51 items for psychological condition were investigated

\begin{tabular}{|c|c|c|c|}
\hline & \multirow[b]{2}{*}{ No } & \multicolumn{2}{|c|}{ No of positive responses } \\
\hline & & Physical items & Psychological items \\
\hline $\begin{array}{l}\text { VWF(+) group } \\
\text { VWF (-) group } \\
\text { Control group }\end{array}$ & $\begin{array}{l}20 \\
20 \\
20\end{array}$ & $\begin{array}{l}53.0 \pm 12 \cdot 2^{\star \star} \\
51.2 \pm 16.2^{\star \star} \\
16.5 \pm 11.6\end{array}$ & $\begin{aligned} 14.5 & \pm 11.4^{\star \star} \\
13.7 & \pm 10.5^{\star \star} \\
3.0 & \pm 5.3\end{aligned}$ \\
\hline
\end{tabular}


Table 3 Variations in $R-R$ interval at rest and during deep breathing (five seconds in and five seconds out). Coefficient of variation is obtained by dividing the standard deviation by mean value

\begin{tabular}{|c|c|c|c|c|c|c|c|}
\hline & \multirow[b]{2}{*}{ No } & \multicolumn{3}{|l|}{ At rest } & \multicolumn{3}{|c|}{ During deep breathing } \\
\hline & & $\begin{array}{l}\text { Mean } \\
\text { (ms) }\end{array}$ & $\begin{array}{l}\text { Standard } \\
\text { deviation } \\
\text { (ms) }\end{array}$ & $\begin{array}{l}\text { Coefficient } \\
\text { of variation } \\
(\%)\end{array}$ & $\begin{array}{l}\text { Mean } \\
\text { (ms) }\end{array}$ & $\begin{array}{l}\text { Standard } \\
\text { deviation } \\
\text { (ms) }\end{array}$ & $\begin{array}{l}\text { Coefficient } \\
\text { of variation } \\
(\%)\end{array}$ \\
\hline $\begin{array}{l}\text { VWF(+) group } \\
\text { VWF ( - ) group } \\
\text { Control group }\end{array}$ & $\begin{array}{l}20 \\
20 \\
20\end{array}$ & $\begin{array}{l}980 \pm 123 \\
951 \pm 97 \\
954 \pm 145\end{array}$ & $\begin{array}{l}18.9 \pm 7.8^{\star} \\
22.4 \pm 6.8 \\
27.1 \pm 11.5\end{array}$ & $\begin{array}{l}1.91 \pm 0.67^{\star \star} \\
2.38 \pm 0.74 \\
2.84 \pm 1.03\end{array}$ & $\begin{array}{l}959 \pm 92 \\
952 \pm 96 \\
970 \pm 135\end{array}$ & $\begin{array}{l}43 \cdot 2 \pm 17 \cdot 4 \\
55.3 \pm 26.5 \\
49 \cdot 2 \pm 19.9\end{array}$ & $\begin{array}{l}4 \cdot 50 \pm 1 \cdot 75 \\
5 \cdot 83 \pm 2 \cdot 74 \\
5 \cdot 25 \pm 2 \cdot 48\end{array}$ \\
\hline
\end{tabular}

${ }^{\star} \mathrm{p}<0.05 ;{ }^{\star \star} \mathrm{p}<0.01$ compared with control group.

group, and the control group in either the resting or deep breathing states. The standard deviation and the $\mathrm{CV}$ of the VWF $(+)$ group at rest were smaller than those of the control group $(p<0.05, p<0.01$ respectively). The standard deviation and the $\mathrm{CV}$ of the VWF $(-)$ group at rest were also smaller than those of the control group; however, the differences were not significant. The standard deviation and the CV during deep breathing were smallest in the $\mathrm{VWF}(+)$ group, followed by those of the control group, and largest in the $\operatorname{VWF}(-)$ group. These differences were not significant.

Table 4 shows the correlations of the $C V$ of the $R-$ $R$ interval, to age and to years exposed to vibration. The correlations to years exposed to vibration were evaluated with a partial correlation coefficient standardised by age, because the CV of R-R interval is affected by age. ${ }^{8}$ Significant correlation with age was observed only for CV during deep breathing in the control group ( $p<0.05)$. Partial correlation coefficients between CVs of $R-R$ interval and years exposed to vibration were observed to be negative in both states, and that during deep breathing was statistically significant $(p<0.05)$.
Table 5 shows the changes of finger skin temperature and blood pressure during the cold exposure test. The values of finger skin temperature in this table were measured just before sampling blood and those of blood pressure were measured five minutes before sampling. The finger skin temperatures at rest and when exposed to cold were lowest in the $\operatorname{VWF}(+)$ group followed by the VWF(-) group. Compared with the control, significant differences were observed for the VWF $(+)$ group at rest and when exposed to cold ( $\mathrm{p}<0.05$. $\mathrm{p}<0.01$ ), and for the $\mathrm{VWF}(-)$ group at rest $(\mathrm{p}<0.05)$. The blood pressure of $\operatorname{VWF}(+)$ and VWF $(-)$ groups tended to be higher than that of the control group, especially at rest period; however, the differences were not significant.

Table 6 shows the responses of the plasma cyclic AMP level to cold exposure. The cyclic AMP levels at rest and during exposure to cold tended to be larger in the VWF $(+)$ and the VWF $(-)$ group than in the control group. The differences, however, were not significant. The increase of the cyclic AMP levels induced by exposure to cold were statistically significant in all three groups and the percentage

Table 4 Correlation coefficient between coefficient of variation ( $C V$ ) of $R-R$ interval and age, and partial correlation coefficient between $C V$ and years exposed to vibration controlled by age

\begin{tabular}{|c|c|c|c|c|c|}
\hline & \multirow[b]{2}{*}{ No } & \multicolumn{2}{|c|}{$\begin{array}{l}\text { Correlation coefficient between } \\
\mathrm{CV} \text { and age }\end{array}$} & \multicolumn{2}{|c|}{$\begin{array}{l}\text { Partial correlation coefficient between } \\
C V \text { and years exposed to vibration }\end{array}$} \\
\hline & & At rest & Deep breathing & At rest & Deep breathing \\
\hline $\begin{array}{l}\text { VWF }(+) / V W F(-) \text { group } \\
\text { Control group }\end{array}$ & $\begin{array}{l}40 \\
20\end{array}$ & $\begin{array}{r}-0.13 \\
0.01\end{array}$ & $\begin{array}{l}-0.04 \\
-0.59^{\star \star}\end{array}$ & $-0 \cdot 20$ & $-0.30^{\star}$ \\
\hline
\end{tabular}

${ }^{\star} \mathrm{p}<0.05 ;{ }^{\star \star} \mathrm{p}<0.01$.

Table 5 Changes of finger skin temperature $\left({ }^{\circ} \mathrm{C}\right)$ and blood pressure $(\mathrm{mm} \mathrm{Hg})$ induced by exposure to cold. Values at rest were measured under atmospheric temperature of test room at $25^{\circ} \mathrm{C}$. Values at exposure were measured after 25 minutes in the cold room at $7^{\circ} \mathrm{C}$

\begin{tabular}{|c|c|c|c|c|c|c|c|}
\hline & \multirow[b]{2}{*}{ No } & \multicolumn{2}{|c|}{ Skin temperature } & \multicolumn{2}{|c|}{ Systolic blood pressure } & \multicolumn{2}{|c|}{ Diastolic blood pressure } \\
\hline & & $\overline{R e s t}$ & Exposure & Rest & Exposure & Rest & Exposure \\
\hline $\begin{array}{l}\text { VWF }(+) \text { group } \\
\text { VWF }(-) \text { group } \\
\text { Control group }\end{array}$ & $\begin{array}{l}20 \\
20 \\
20\end{array}$ & $\begin{array}{l}30 \cdot 6 \pm 3 \cdot 1^{\star \star} \\
32 \cdot 0 \pm 2 \cdot 0^{\star} \\
33 \cdot 2 \pm 1 \cdot 2\end{array}$ & $\begin{array}{l}15 \cdot 3 \pm 1 \cdot 4^{\star} \\
16 \cdot 1 \pm 2 \cdot 8 \\
16 \cdot 4 \pm 1 \cdot 7\end{array}$ & $\begin{array}{l}126.1 \pm 16.4 \\
122.9 \pm 15.3 \\
115.3 \pm 17.4\end{array}$ & $\begin{array}{l}135 \cdot 3 \pm 19 \cdot 8 \\
142.5 \pm 21 \cdot 2 \\
133.3 \pm 20 \cdot 1\end{array}$ & $\begin{array}{l}81 \cdot 9 \pm 10 \cdot 8 \\
81 \cdot 7 \pm 9 \cdot 3 \\
77 \cdot 3 \pm 10 \cdot 2\end{array}$ & $\begin{array}{r}85 \cdot 0 \pm 9 \cdot 1 \\
94.8 \pm 19 \cdot 0 \\
87 \cdot 6 \pm 12 \cdot 1\end{array}$ \\
\hline
\end{tabular}

${ }^{\star} \mathrm{p}<0.05 ;{ }^{\star \star} \mathrm{p}<0.01$ compared with control group. 
Table 6 Responses of plasma cyclic AMP level (pmol/ml) to cold exposure. Values at rest were measured under atmospheric temperature of test room at $25^{\circ} \mathrm{C}$. Values at exposure were measured after 25 minutes in the cold room at $7^{\circ} \mathrm{C}$

\begin{tabular}{|c|c|c|c|c|c|}
\hline & No & Rest & Exposure & Increase & $\%$ Increase \\
\hline $\begin{array}{l}\text { VWF }(+) \text { group } \\
\text { VWF }(-) \text { group } \\
\text { Control group }\end{array}$ & $\begin{array}{l}20 \\
20 \\
20\end{array}$ & $\begin{array}{l}14 \cdot 7 \pm 2 \cdot 2 \\
15 \cdot 1 \pm 2 \cdot 1 \\
14 \cdot 2 \pm 2 \cdot 7\end{array}$ & $\begin{array}{l}16 \cdot 6 \pm 2 \cdot 7 \\
17 \cdot 5 \pm 2 \cdot 4 \\
16 \cdot 1 \pm 3 \cdot 6\end{array}$ & $\begin{array}{l}1.9 \pm 2 \cdot 2^{\star \star} \\
2 \cdot 3 \pm 1 \cdot 9^{\star \star} \\
1.9 \pm 2 \cdot 6^{\star \star}\end{array}$ & $\begin{array}{l}14 \cdot 0 \pm 16 \cdot 3 \\
16 \cdot 4 \pm 15 \cdot 0 \\
14.3 \pm 22 \cdot 3\end{array}$ \\
\hline
\end{tabular}

Table 7 Responses of plasma cyclic GMP level (pmol $/ \mathrm{ml}$ ) to cold exposure. Values at rest were measured under atmospheric temperature of test room at $25^{\circ} \mathrm{C}$. Values at exposure were measured after 25 minutes in the cold room at $7^{\circ} \mathrm{C}$

\begin{tabular}{|c|c|c|c|c|c|}
\hline & No & Rest & Exposure & Increase & $\%$ Increase \\
\hline $\begin{array}{l}\text { VWF(+) group } \\
\text { VWF ( - ) group } \\
\text { Control group }\end{array}$ & $\begin{array}{l}20 \\
20 \\
20\end{array}$ & $\begin{array}{l}4.8 \pm 1.5 \\
5.1 \pm 1.9 \\
5.9 \pm 2.7\end{array}$ & $\begin{array}{l}5.8 \pm 1.8 \\
6.3 \pm 2.6 \\
6.5 \pm 3.2\end{array}$ & $\begin{array}{l}1 \cdot 0 \pm 1 \cdot 4^{\star \star} \\
1 \cdot 1 \pm 1 \cdot 6^{\star \star} \\
0.6 \pm 1 \cdot 2^{\star \star}\end{array}$ & $\begin{array}{c}23 \cdot 5 \pm 28 \cdot 1^{\star} \\
25 \cdot 5 \pm 28 \cdot 6^{\star} \\
9 \cdot 5 \pm 20 \cdot 0\end{array}$ \\
\hline
\end{tabular}

${ }^{\star} \mathrm{p}<0.05$ compared with control group; ${ }^{\star \star} \mathrm{p}<0.01$ compared between rest and exposure.

increase was almost the same among the three groups.

Table 7 shows the responses of the cyclic GMP level to exposure to cold. The cyclic GMP level at rest condition was smallest in the $\mathrm{VWF}(+)$ group followed by the VWF(-) group and largest in the control group. The differences between the $\mathrm{VWF}(+)$ group and the VWF(-) group, and the control group did not quite achieve the conventional levels of significance, 0.052 and 0.051 , respectively. The increase of the cyclic GMP levels induced by exposure to cold were statistically significant in the $\operatorname{VWF}(+)$ and the VWF $(-)$ groups $(\mathrm{p}<0.01)$. That of the control group was small and was not statistically significant. The percentage increases of the $\operatorname{VWF}(+)$ and the $\operatorname{VWF}(-)$ groups were larger than that of the control group ( $\mathrm{p}<0.05$ ).

Table 8 shows the correlations of the percentage increase of cyclic GMP level to the changes of finger skin temperature and systolic blood pressure induced by exposing the whole body to cold and the coefficient of variation of the $R-R$ interval during deep breathing. In the control group the percentage increase of plasma cyclic GMP level had a positive correlation with the coefficient of variation of the $\mathrm{R}-\mathrm{R}$ interval during deep breathing $(\mathrm{p}<0.01)$. By contrast, in the VWF $(+)$ group the percentage increase of plasma cyclic GMP level had positive correlations with the decrease of finger skin tem- perature $(0.05<p<0.10)$ and the increase of sys $-\overrightarrow{+}$ tolic blood pressure $(p<0.05)$.

\section{Discussion}

The purpose of the CMI questionnaire is to collect a large body of pertinent medical and psychiatric data. ${ }^{10}$ It is useful for a comprehensive evaluation of ${ }^{2}$ the patient's condition. In Japan the original version, revised in 1955, was translated into Japanese with slight modification and it has been widely used. ${ }^{12}$ The results of the CMI study indicated that patients with vibration syndrome not only have disturbances in the arms but also various generalised symptoms. This coincides with the results of Matoba's study of $\stackrel{\mathbb{Q}}{\circ}$ subjective complaints of central nervous function by patients with vibration syndrome. ${ }^{1}$ These are subjective findings, however, and objective evidence is required.

Differences in the mean value of $R-R$ intervals between the patient groups (VWF $(+)$ group and 9 VWF (-) group) and the control group were not $>$ observed. In our previous study mean values of the $R-R$ interval of workers exposed to vibration were $N$ larger than those of the control. ${ }^{8}$ The bradycardia in patients with vibration syndrome was pointed out 0 and it was considered to result from the adaptive $\omega$ response of the cardiovascular system to their hard

Table 8 Correlation coefficients of the percentage increases of plasma cyclic GMP levels to the changes of finger skin temperature, the systolic blood pressure, and the coefficient of variation of $R-R$ interval during deep breathing

\begin{tabular}{|c|c|c|c|c|}
\hline & No & $\begin{array}{l}\text { Decrease of finger } \\
\text { skin temperature }\end{array}$ & $\begin{array}{l}\text { Increase of systolic } \\
\text { blood pressure }\end{array}$ & $\begin{array}{l}\text { Coefficient of variation } \\
\text { of } R-R \text { interval }\end{array}$ \\
\hline $\begin{array}{l}\text { VWF(+) group } \\
\text { VWF (-) group } \\
\text { Control group }\end{array}$ & $\begin{array}{l}20 \\
20 \\
20\end{array}$ & $\begin{array}{r}0.37 \\
0.01 \\
-0.37\end{array}$ & $\begin{array}{r}0.39 \star \\
-0.07 \\
-0.29\end{array}$ & $\begin{array}{c}0.04 \\
-0.31 \\
0.58 \star \star\end{array}$ \\
\hline
\end{tabular}


work. ${ }^{13}$ In this study all the subjects in the $\operatorname{VWF}(+)$ and the $\mathrm{VWF}(-)$ groups were patients under medical treatment who had stopped work several years earlier. The adaptation effects had presumably disappeared by the time of this investigation.

Respiratory sinus arrhythmia is vagally mediated and the variation of the $R-R$ interval of $E C G$ resulting from respiratory arrhythmia is regarded as an indicator of parasympathetic function..$^{14}$ The $\mathrm{CVs}$ of the $\mathrm{VWF}(+)$ group were smaller than those of the control group in both the resting and deep breathing state. The difference of the $\mathrm{CV}$ between the VWF(+) group and the control group was statistically significant during resting but not during deep breathing. The reduced $\mathrm{CV}$ in the VWF $(+)$ group indicates hypofunction of the parasympathetic nervous system. Our previous study showed a similar result $^{8}$; however, the difference between the workers exposed to vibration and the healthy subjects was significant only during deep breathing and not in the resting state. Interestingly the $\mathrm{CV}$ of the control group in this study was much smaller than that of the previous study and resulted from the difference of 13 years in mean age of the subjects, which was 42.6 years in the previous study and 55.6 in the current study. The difference of the $\mathrm{CV}$ findings between the two studies may be related to the effects of aging. As a result of standardisation of age, negative correlations between $\mathrm{CV}$ and years exposed to vibration were observed in the $\operatorname{VWF}(+) / \operatorname{VWF}(-)$ group. This emphasises that the reduced $\mathrm{CV}$ is caused by exposure vibration. Similar results concerning heart rate variation have also been reported by Heinonen $e t$ $a l^{\circ}$ and Kobayashi et al. ${ }^{7}$ These findings indicate that the basal tone of the parasympathetic nervous system of patients with vibration syndrome is decreased.

Cyclic AMP and cyclic GMP are second messengers in cells and their levels in the blood are regarded as indicators of autonomic nervous function. ${ }^{16}$ The interindividual variations are so large that the assessment of the change of levels induced by physiological stress is recommended. ${ }^{17}$ In this study exposure of the whole body to cold induced a significant increase in the cyclic AMP level. When immersing a hand in cold water, the significant response of cyclic AMP was not confirmed ${ }^{17}$; however, when the whole body was exposed to cold it was observed. ${ }^{18}{ }^{10}$ Since the response to physical stresses is inhibited by beta antagonists, the change of plasma cyclic AMP level is considered to reflect sympathetic nervous function, especially beta receptor function. ${ }^{17}{ }^{18}$ In this study the response of cyclic AMP was almost the same among the three groups. We observed that the response of plasma norepinephrine level to whole body exposure to cold was activated in the patients with vibration syndrome. ${ }^{20}$ Norepinephrine has a greater effect, much more than the beta receptor, on the sympathetic alpha receptor. ${ }^{21}$ Furthermore, contraction of the smooth muscle of vessels is caused by activation of the alpha-adrenergic mechanism. ${ }^{22}$ Therefore, we speculate that the alpha adrenergic receptor system is more readily activated than the beta adrenergic receptor system in patients with vibration syndrome.

The increase of plasma cyclic GMP level induced by exposing the whole body to cold was greater in the groups of patients than in the controls. This result confirms the report by Okada et al ${ }^{9}$ who showed that an increase of plasma cyclic GMP levels induced by immersing a hand in cold water was observed in patients with vibration syndrome but not in healthy subjects. Since the increase of plasma cyclic GMP induced by exposing patients with vibration syndrome to cold was inhibited by administration of alpha-2 antagonist or atropine, the increase was speculated to result from the hyperfunction of sympathetic alpha-2 receptors or parasympathetic muscarinic receptor. ${ }^{93}$ Furthermore, the increase of plasma cyclic GMP levels in patients with vibration syndrome was greater after exposure to cold than during exposure $\mathrm{e}^{923}$ and the increase of plasma cyclic GMP level followed the increase of plasma cyclic AMP level in healthy subjects. ${ }^{18}$

Two explanations are possible for the response of plasma cyclic GMP level to exposure to cold. Firstly, the secondary response of the parasympathetic nervous system may be provoked by the response of the sympathetic nervous system. Secondly, the secondary response of the presynaptic alpha- 2 receptor may have a role of negative feedback for inhibition of norepinephrine release in the sympathetic nerve endings. $^{22}$ Because the control group showed a positive correlation between the percentage increase of plasma cyclic GMP level and the CV of the R-R interval, which indicates parasympathetic nervous function, the increase of plasma cyclic GMP level is considered to reflect the response of the parasympathetic nervous system in healthy subjects. Because the $\mathrm{VWF}(+)$ group showed a positive correlation between the percentage increase of plasma cyclic GMP level and the changes of finger skin temperature and systolic blood pressure, the increase of plasma cyclic GMP level is considered largely to reflect the response of the alpha-2 adrenergic mechanism in patients with vibration syndrome with VWF. The VWF $(-)$ group did not show such significant correlations. In the patients with vibration syndrome without VWF the increase of plasma cyclic GMP level may be contributed by both responses of the parasympathetic nervous system and the alpha-2 adrenergic mechanism.

From the above findings, we concluded that basal activity of the parasympathetic nervous system of patients with vibration syndrome is decreased. Exposure to cold induces the secondary hyperresponse of the parasympathetic nervous system and the alpha- 2 adrenergic mechanism in the patients 
with vibration syndrome. In patients with VWF the latter effect is presumably larger than the former.

This work was supported by a grant in aid for scientific research from the Ministry of Education, Science, and Culture of Japan.

1 Matoba T, Kusumoto H, Mizuki Y, Kuwahara H, Inanaga K, Takamatsu M. Clinical features and laboratory findings of vibration disease. Tohoku J Exp Med 1977;123:57-65.

2 Arikawa K, Shirakawa T, Kotorii T, et al. An electroencephalographic study of patients with vibration disease. Folia Psychiatria et Neurologica Japonica 1978;32:211-21.

3 Committee on Vibration Hazards in the Japanese Association of Industrial Health. The publication of the committee work. Tokyo: Japanese Association of Industrial Health, 1980. (In Japanese.)

4 Dupuis H, Gemne G. Hand-arm vibration and the central nervous system. Int Arch Occup Environ Health 1985;55: 185-9.

5 Taylor W, Ogston SA, Brammer AJ. A clinical assessment of seventy-eight cases of hand-arm vibration syndrome. Scand $J$ Work Environ Health 1986;12:265-8.

6 Heinonen E, Färkkilä M, Forsström J, et al. Autonomic neuropathy and vibration exposure in forestry workers. $\mathrm{Br} \mathrm{J}$ Ind Med 1987;44:417-21.

7 Kobayashi F, Watanabe T, Sumi K, et al. Evaluation of autonomic nervous activity in patients with vibration disease using electrocardiographic R-R interval variations. Ind Health 1987;25:83-7.

8 Harada N, Yoshida I, Kimura K. Heart rate variation and serum dopamine-beta-hydroxylase activity in workers exposed to vibration. Int Arch Occup Environ Health 1989;61:369-73.

9 Okada F, Kiyota N, Honma M, Ui M. Plasma guanosine 3',5'monophosphate responses to the cold pressor test in patients with vibration disease. Arch Environ Health 1983;38:144-7.

10 Brodman K, Erdmann AJ Jr, Lorge I, Wolff HG, Broadbent TH. The Cornell medical index-health questionnaire. II. As a diagnostic instrument. JAMA 1951;145:152-7.

11 Honma M, Satoh T, Takezawa J, Ui M. An ultrasensitive method for the simultaneous determination of cyclic AMP and cyclic GMP in small-volume samples from blood and tissue. Biochem Med 1977;18:257-73.

12 Kanahisa T, Fukamachi S. Cornell medical index. Kyoto: Sankyobo, 1972. (In Japanese.)

13 Matoba $T$, Itaya $M$, Toyomatsu $K$, Tsuiki $T$, Tosima $H, O$ Kuwahara $\mathrm{H}$. Increased left ventricular function as an adaptive response in vibration disease. Am J Cardiol 1983;51: 1223-6.

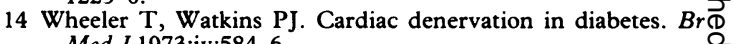
Med J 1973;iv:584-6.

15 Wieling W, Karemaker JFM. Borst C, Dunning AJ. Testing for autonomic neuropathy: heart rate response to forced breathing. Clin Physiol 1985;5 suppl:28-33.

16 Ui M, Honma M, Kunitada S, et al. Adrenergic and cholinergic ${ }_{-}^{-}$ modulation of extracellular cyclic nucleotides. Advances in $\overrightarrow{-}$ Cyclic Nucleotide Research 1980;12:25-35.

17 Okada F, Honma M, Ui M. Changes in plasma cyclic nucleotides levels during various acute physical stresses. Horm Metab Res 1980;12:80-3.

18 Mikuni M, Daiguji M, Koyama T, Saito Y. Effect of cold and emotional stresses on plasma cyclic nucleotides of normal adults. Psychiatria et Neurologia Japonica 1980;82:444-7. (In+A Japanese.)

19 Prikryl P, Ryšánek K, Továrek J, et al. Effects of cold stress on O catecholamines, cyclic AMP and cyclic GMP in hardened and $\omega$ unhardened men. Activitas Nervosasuterior Supplement $\mathrm{O}$ (Praha) 1982;24:32-3.

$20 \mathrm{Kondo} \mathrm{H}$. Functions of the sympathetic-adrenomedullar system and adrenocortex in patients with vibration syndrome Japanese Journal of Industrial Health 1988;30:263-71. (In음 Japanese with English abstract.)

21 Weiner N. Norepinephrine, epinephrine, and the sympatho- $\vec{\theta}$ mimetic amines. In: Gilman AG, Goodman LS, Rall TW, Murad F, eds. The pharmacological basis of therapeutics. 7th ed. New York: Macmillan, 1985:145-80.

22 Weiner $\mathrm{N}$, Taylor $\mathrm{P}$. Neurohumoral transmission: the auto-O nomic and somatic motor nervous systems. In: Gilman AG, Goodman LS, Rall TW, Murad F, eds. The pharmacological basis of therapeutics. 7th ed. New York: Macmillan, 1985:O 66-99.

23 Kiyota K, Fujisawa T, Okada F. Plasma cyclic nucleotide $\mathbb{D}$ response in patients with vibration disease. Japanese Journal of Traumatollogy and Occupational Medicine 1987;35:44-51. (In $\overrightarrow{\overrightarrow{\vec{A}}}$ Japanese with English abstract.)

Accepted 18 May 1989 